\title{
Divergent evolution of wheat populations conducted under recurrent selection and dynamic management
}

\author{
Isabelle Goldringer ${ }^{a^{*}}$, Sophie Paillard ${ }^{a}$, Jérôme Enjalbert ${ }^{\mathrm{a}}$, \\ Jacques L. David ${ }^{\mathrm{b}}$, Philippe Brabant ${ }^{\mathrm{a}, \mathrm{c}}$ \\ ${ }^{a}$ Inra, Ina-PG UPS, Station de génétique végétale, Ferme du Moulon, 91190 Gif-sur-Yvette, France \\ ${ }^{\mathrm{b}}$ Ensam Inra UFR de génétique et amélioration des plantes, Domaine de Melgueil, 34130 Mauguio, France \\ ${ }^{c}$ Ina-PG, 16 rue Claude Bernard, 75005 Paris, France
}

(Received 4 November 1997; accepted 5 July 1998)

\begin{abstract}
The effects of artificial selection in a recurrent selection programme (RS) and natural selection in a dynamic management programme (DM) were studied in a wheat composite population. The initial population, populations of different cycles of RS and four populations of DM were compared for agromorphological traits. It is shown that DM and RS led to divergent evolution of the populations that could be sharply distinguished by few traits: plant height, earliness, frequency of bearded plants and susceptibility to powdery mildew and leaf rust. Except for plant height, genetic variability was maintained in the DM system either within the populations or through the differentiation between populations. Variability was also preserved in the RS programme except for leaf rust resistance for which the strong increase of resistance level led to a loss of genetic variability. Compared with RS, DM could have selected more multigenic resistances and conserved a larger diversity of resistance genes. Conditions for the possible use of the DM populations as a source of variability for the RS programme are discussed. We suggest the introduction of artificial selection in some DM populations in order to preserve their 'cultivated' phenotype. In DM, the benefit of multiplication sites with high and contrasting parasitic pressures is emphasized. (C Inra/Elsevier, Paris.)
\end{abstract}

recurrent selection / dynamic management / Triticum aestivum / genetic variability / local adaptation / wheat population

Résumé - Évolution divergente de populations de blé en sélection récurrente et en gestion dynamique. Les effets de la sélection sont étudiés sur une population composite de blé : sélection artificielle dans un programme de sélection récurrente (RS) et sélection naturelle dans un programme de gestion dynamique (DM). La population initiale, des populations de différents cycles de RS, et des populations maintenues huit années dans quatre environnements en DM, sont comparées pour des caractères agro-mrophologiques. Il est montré que RS et DM conduisent à des évolutions divergentes des populations. Peu de caractères (hauteur des plantes, précocité, fréquence de plantes barbues, sensibilité à l'oïdium et

Communicated by Max Rives (Villeneuve-lès-Avignon, France)

* Correspondence and reprints

E-mail: isa@moulon.inra.fr. 
à la rouille brune) suffisent à différencier les populations issues des deux systèmes. Sauf pour la hauteur, la variabilité génétique a été conservée en GD, soit à l'intérieur des populations, soit grâce à la structuration entre populations. La variabilité a été préservée également en RS sauf pour la résistance à la rouille brune, pour laquelle l'augmentation forte du niveau de résistance s'est accompagnée d'une perte de variabilité. En comparaison, DM pourrait avoir conduit à la sélection de mécanismes plus multigéniques et à la conservation d'une plus grande diversité de gènes de résistance. Les conditions pour une utilisation des populations DM comme source de variabilité pour le programme RS sont discutées. Il est proposé d'introduire une sélection artificielle dans certaines populations de DM afin d'en préserver les caractéristiques " cultivées ». L'intérêt en DM, de sites de multiplication présentant de fortes pressions parasitaires contrastées est souligné. (@ Inra/Elsevier, Paris.)

\section{sélection récurrente / gestion dynamique / Triticum aestivum / variabilité génétique / adaptation locale}

\section{INTRODUCTION}

To maintain a steady progress in the long term in plant breeding, it is necessary to organize a continuous gene flow to enrich the elite germ plasm under intensive selection, with favourable alleles scattered among different genotypes of the unadapted germ plasm. Since primitive varieties, land races or wild relatives are not adapted to modern agriculture, the valuable alleles found in these resources cannot be directly transferred into modern varieties. Indeed, unadapted germ plasm might transmit genetic defects in addition to the desired genes. Backcross and subsequent selection proved to be very effective for the transfer of characteristics with discrete variation under the control of one or a few genes. However, in the case of continuous variation of multigenic traits such as adaptation to climatic or edaphic stress or some disease resistances [23] that may also express epistasis, backcrossing was unreliable until recently. New modified backcross methods, based on marker-assisted selection, have recently been proposed $[18,30]$ to monitor the transfer of more complex traits from unadapted germ plasm to elite lines. We believe, however, that an integrative breeding strategy based on population management and recurrent selection, as proposed by Gallais [11], is a more relevant methodology to fulfil a continuous and sizeable transfer of partially characterized variability from primitive varieties and land races to elite genotypes. Twenty years ago such a strategy was initiated on bread wheat at the Institut national de la recherche agronomique (Inra) with the launching of several recurrent selection programmes $[2,31,32]$. A few years later, Inra and the Direction générale de l'enseignement et de la recherche du Ministère de l'agriculture (Dger) began supporting this effort with the establishment of a pilot programme described as 'dynamic management of genetic resources' [17].

The aims of recurrent selection (RS) are to continuously improve a population by means of successive cycles of selection and recombination and to derive elite lines from the improved population. Recurrent selection was first successfully developed in outcrossing crop species (see [15] for a review), but for some years it has also been applied to self-pollinated species (see [20] and [12] for review). Because genetic variability may decrease in the course of the successive cycles [3, 24, 28], and at the same time in order to integrate new genes missing in the founder parents of the population, introducing new variability has to be considered during the recombination phase of each cycle. Sources of interesting genes complementary to those present in the population must then be identified and the rate of introgression monitored.

The principle of dynamic management (DM) is to permit the evolution and the adaptation of different polymorphic wheat populations to a wide range of environmental conditions. Genetic variability may decrease in each site but the initial diversity is expected to be maintained through the structuring between the local populations. Such a programme may be seen as a means to recreate land races adapted to today's climatic and parasitic constraints. Hence, they may constitute a source of variability to enrich populations under recurrent selection. To test this, we must characterize the genetic material 
obtained from both systems, recurrent selection and dynamic management, for agromorphological traits as well as for neutral markers.

Here, we present the first experiment to comparing i) populations from different stages (cycles 2, 3 and 4) of a recurrent selection scheme and ii) populations derived from eight generations of multiplication in the dynamic management programme. Our aims were to compare the evolution for the means and for the variances of agromorphological traits in these polymorphic populations that share the same genetic origin. We also discuss the ability of the two systems to preserve genetic variability and judge whether populations maintained under dynamic management may be used as sources of variability for recurrent selection.

\section{MATERIALS AND METHODS}

\subsection{Origin of the populations}

All the populations studied were derived from the same initial wheat composite population (PA0). In 1975, 16 European cultivars or elite inbred lines selected at Inra but including very varied pro-genitors (e.g. VPM [8] and Norin 10) in their pedigree, were crossed in a pyramidal way to create PA0 [31]. Though the agronomic level of the parents was satisfactory, especially for some disease resistances, the genetic basis was broad enough so that long-term genetic advance could be expected. The whole set of populations derived by whatever means from PA0 will be referred to as genetic pool PA. In this study, we examined eight PA populations: PA0, three populations derived through recurrent selection and four populations derived through dynamic management.

Recurrent selection has been applied since 1979 on PA within a multisite experimental network (ClermontFerrand, Le Moulon [near Paris], Rennes). Selection for disease resistances evaluated in nursery with no fungicides, plant height, earliness, grain yield under intensive conditions and bread-making value was performed at each cycle according to different multitrait selection procedures [2,32]. The cycle lasted 3 years with 2 years devoted to selection (on $S_{0}$ plants and $S_{1}$ families) and 1 year to the crossing of $S_{2}$ plants representative of 80 selected $S_{1}$ families. In the third cycle, 15 exogenous lines were introduced and mixed with the selected families by means of 2 consecutive years of intercrossing (Trottet, personal communication). About $14 \%$ of the plants derived from the intercrossing of the third cycle (PA-RS3 population) had one of the exogenous lines as progenitor. Three populations coming from the recurrent selection scheme have been studied: PA-RS2, PA-RS3 and PA-RS4 derived by bulk multiplication from the crossing in the second, third and fourth cycle, respectively.

The initial composite population PA0 was also used for the dynamic management programme [17, 25]. In 1984 , after three generations of bulk multiplication, PA0 was distributed to the seven sites of a French network composed of the experimental stations of agricultural universities and schools, and Inra stations. At each site, two different agricultural conditions were applied: an intensive farming method and a more extensive one, closer to durable agricultural objectives (one third of the nitrogen fertilizers used in the intensive condition and no fungicide treatments). The population (about 10000 individuals) at a given site conducted under one farming method was grown in isolation from other wheat culture. Each year, it was harvested separately and a sample of the seed was used for sowing the next year's population. Although wheat is predominantly selfing, a significant outcrossing rate $(2.1-10.6 \%)$ was estimated in the different DM populations [9]. Hence, a certain amount of recombination is allowed within each population. After 8 years of multiplication, four populations developed through the dynamic management programme were sampled for this study: two populations originated from Le Moulon (PA-DMM populations) and two from Rennes (PA-DMR populations) with either the intensive farming condition (PA-DMMI and PA-DMRI) or the extensive one (PA-DMME and PA-DMRE).

\subsection{Experimental procedure}

The eight PA populations (PA0, three PA-RS and four PA-DM) and four pure lines used as control were evaluated in a complete block design with four replications (or eight for the RS populations) at Le Moulon in 1993. In each block, each population was grown in a $1 \mathrm{~m}^{2}$ plot of about 50 spaced plants (between-row: $20 \mathrm{~cm}$; withinrow: $10 \mathrm{~cm}$ ) that were individually observed. The total number of plants measured was 201 for PA0, 269 for PA-RS2, 362 for PA-RS3, 402 for PA-RS4, 213 for PADMME, 205 for PA-DMMI, 209 for PA-DMRE and 210 for PA-DMRI. The following traits were measured: heading date (HD), recorded as the number of days after 1 May; plant height $(\mathrm{PH}, \mathrm{cm})$; awn characteristics ( $\mathrm{AW}$, scale from 1 [awnless] to 5 [bearded]); leaf rust susceptibility (LR, scale from 1 [resistant] to 9 [completely sus- 
ceptible]), powdery mildew susceptibility (PM, scale from 0 [resistant] to 9 [completely susceptible]), recorded on only three replications; grain weight per spike (GW, g), averaged over three spikes per plant. One spike per plant was harvested and the seed was bulked for each plot; kernel weight $(\mathrm{KW}, \mathrm{mg})$ was measured on these seed samples of the plots so that no individual plant data were available for this trait.

\subsection{Statistical analysis}

We first compared all the populations as a whole for all traits to assess their range and whether there was any differentiation. Then, for each trait we focused on the different subsets of populations in which we had previously found some differentiation.

\subsubsection{Comparison of the population means}

The following analysis of variance (ANOVA) model was used to compare all the populations:

$$
Y_{i j k}=\mu+b l_{i}+p o p_{j}+(b l \times p o p)_{i j}+R_{i j k}
$$

for every trait except for kernel weight (KW). As KW had only been measured at the whole plot level, it was analyzed according to the simpler ANOVA model:

$$
Y_{i j}=\mu+b l_{i}+p o p_{j}+R_{i j}
$$

where $Y_{i j k}$ (respectively, $Y_{i j}$ ) is the response of plant $k$ in population $j$ measured in block $i$ (respectively, plot mean of population $j$ measured in block $i$ ), $\mu$ the general mean of the populations, $b l$ the fixed block effect, pop the fixed population effect and $R$ the random residual term. If we assume that there is no block $\mathrm{x}$ population interaction, $(b l \times p o p)$ is the random plot effect. For every trait except $\mathrm{KW}$, population means were compared with the Student-Newmans-Keuls (SNK) multiple range test with an experiment-wise error rate of $5 \%$. In the comparison as well as in the ANOVA, the test of the population effect was carried out using ( $b l \times$ pop) as the error term. As cell sizes were too markedly unequal between GD and RS for KW, we used a Tukey-Kramer test (studentized range modified for unequal cell sizes [21]).

To compare the four populations under dynamic management, the pop effect in the initial ANOVA model was partitioned into a site (si) effect and a farming condition $\left(f_{c}\right)$ effect:

$$
Y_{i j k l}=\mu+b l_{i}+s i_{j}+f c_{k}+(b l \times s i \times f c)_{i j k}+R_{i j k l}
$$

For the global comparison of the two systems (RS and DM), the null hypothesis of the contrast between the four DM populations and the three RS populations was tested in the first ANOVA model. The contrast between the four DM populations and PA0 was also performed to test the significance of slight differences that were not detectable in the overall comparison. In all these ANOVA, the principal effects were tested using the appropriate interaction or nested effect as the error term.

\subsubsection{Comparison of the populations distributions for a non-Gaussian trait}

Leaf rust resistance (LR) displayed a strongly nonGaussian distribution with an L shape (data not shown). Moreover, some of the populations showed close means (not significantly different), but their distributions seemed quite different. Hence, to test the non-homogeneity of the LR distributions between populations, a $\chi^{2}$ statistics was computed on the frequencies of the LR categories (after pooling the low frequency categories). If $n$ is the number of populations to be compared, the level of significance for each comparison was set to a value of $0.05 /[n(n-1) / 2]$.

\subsubsection{Comparison of within-populations variances}

For every trait except KW, the within-population total variances $\left(\hat{\sigma}_{T W}^{2}\right)$ were assessed as the residual variances of the ANOVA performed individually on each population. The within-population genetic variances $\left(\hat{\sigma}_{G W}^{2}\right)$ were inferred as $\hat{\sigma}_{G W}^{2}=\hat{\sigma}_{T W}^{2}-\hat{\sigma}_{E W}^{2}$ with $\hat{\sigma}_{E W}^{2}$ the withinplot environmental variances. For $\mathrm{HD}, \mathrm{PH}, \mathrm{AW}$ and $\mathrm{GW}$ traits, $\hat{\sigma}_{E W}^{2}$ was estimated by the means of the four pure lines used as control. For LR, only a global estimation of the resistance was made on the controls and $\hat{\sigma}_{G W}^{2}$ could not be calculated. For PM, eight additional specific lines were used as controls in the trial. The study of the relationship between environmental variance and mean for $P M$ on the 12 varieties led us to the determination of three categories of genotypes: those with mean $\mathrm{PM} \leq 2$ and low variance (1), those with $2<\mathrm{PM} \leq 6.5$ and large variance (2), and those with $\mathrm{PM}>6.5$ and low variance (3). An environmental variance was calculated for each of the three categories $\left(\hat{\sigma}_{E W 1}^{2}, \hat{\sigma}_{E W 2}^{2}, \hat{\sigma}_{E W 3}^{2}\right)$. For each population, the frequencies of individuals in each category were computed (on the adjusted data) and then $\hat{\sigma}_{T W}^{2}$ was estimated in each population as the weighted mean of 
$\hat{\sigma}_{E W 1}^{2}, \hat{\sigma}_{E W 2}^{2}$ and $\hat{\sigma}_{E W 3}^{2}$, considering the proportions of genotypes in the three categories. Confidence intervals for $\hat{\sigma}_{T W}^{2}$ and $\hat{\sigma}_{E W}^{2}$ were calculated using the Gaussian approximation of the $\chi^{2}$ distribution of the residual mean square. Confidence intervals for $\hat{\sigma}_{G W}^{2}$ were then inferred from the previous ones.

For the DM populations, the between-population genetic variance could be calculated with the first ANOVA model applied to the four DM populations, as $\hat{\sigma}_{G B}^{2}=\left(\mathrm{CM}_{\mathrm{pop}}-\mathrm{CM}_{\mathrm{blxpop}}\right) / \overline{n p}$, with $\overline{n p}$ the average number of plants per population. For HD and AW in particular, the total genetic variances of the four DM populations were then estimated as $\hat{\sigma}_{G B}^{2}+\hat{\sigma}_{G W}^{2}$.

\subsubsection{Multivariate analysis}

Finally, a canonical discriminant analysis was performed on the six variables $\mathrm{HD}, \mathrm{PH}, \mathrm{AW}, \mathrm{LR}, \mathrm{PM}$ and GW. The set of data was restricted to the three replications (893 observations) on which PM had been measured.

\section{RESULTS}

\subsection{Evolution of the agromorphological traits}

The overall comparison showed a strong differentiation for heading date (HD, table I). The DM populations and the RS populations of the third and fourth cycles had become significantly different for their earliness. The four DM populations were either close to PA0 (PA-DMMI and PA-DMRE) or they were later than PA0 (PA-DMME and PADMRI). Though some of the DM populations were significantly different from each other, they did not show any site or farming condition effect (data not shown). This trend for later heading in those four DM populations that had been evolving in the north is consistent with previous results $[6,22]$ on DM populations originated from sites from all over the French territory. The authors showed that earliness had been evolving according to the latitude of the multiplication site: populations from the north became genetically later than PA0 whereas populations from the south became earlier. Figure 1 shows that genetic within-population variance simultaneously decreased in the four DM populations. Local adaptation led to a loss of within-population variability. On the other hand, the RS populations evolved towards a higher earliness. The PA-RS2 population was earlier than PA0, and the populations of the two last cycles (PA-RS3 and PA-RS4) were significantly earlier than PA-RS2 (table I). Though only soft stabilizing selection had been applied on earliness in the RS scheme, the results showed a progressive shortening of the development cycle, which was associated with an increase of the within-population genetic variability figure 1). This latter point could be explained by the multisite aspect of the selection. The Rennes and Le Moulon locations might favour the expression and hence the selection of middle to late genotypes whereas Clermont-Ferrand (centre of France) might lead to the selection of earlier genotypes.

The eight populations also proved to be highly differentiated for plant height (PH, table I). The four DM populations significantly increased in height with regard to PA0 whereas the populations of the two last RS cycles (PA-RS3 and PA-RS4) became significantly shorter than PA0. Among the DM populations, only PA-DMME could be distinguished from the others and neither a site effect nor a farming condition effect was detected (data not shown). This increase in height observed in the DM populations (up to more than $20 \mathrm{~cm}$ for three of them) is mainly due to competition for light between individuals within populations. David et al. [6] and Le Boulc'h et al. [22] have shown that this led to a monodirectional evolution of all the populations in the network. Moreover, the genetic within-population variance had decreased for three of the four DM populations (figure 1). On the other hand, taller plants had been strongly counterselected in the RS scheme as the objectives of selection for $\mathrm{PH}$ were around an optimum of $85 \mathrm{~cm}$. The rapid decrease of the genetic within-population variance during the second and third cycles was then followed by a slight increase in the fourth cycle (figure 1). Actually, the tallest plants were drastically eliminated in the second and third cycles (the distribution becoming narrower; data not shown), whereas in the fourth cycle, the extremes remained the same but the distribution became more Gaussian with a $80 \mathrm{~cm}$ mode. 


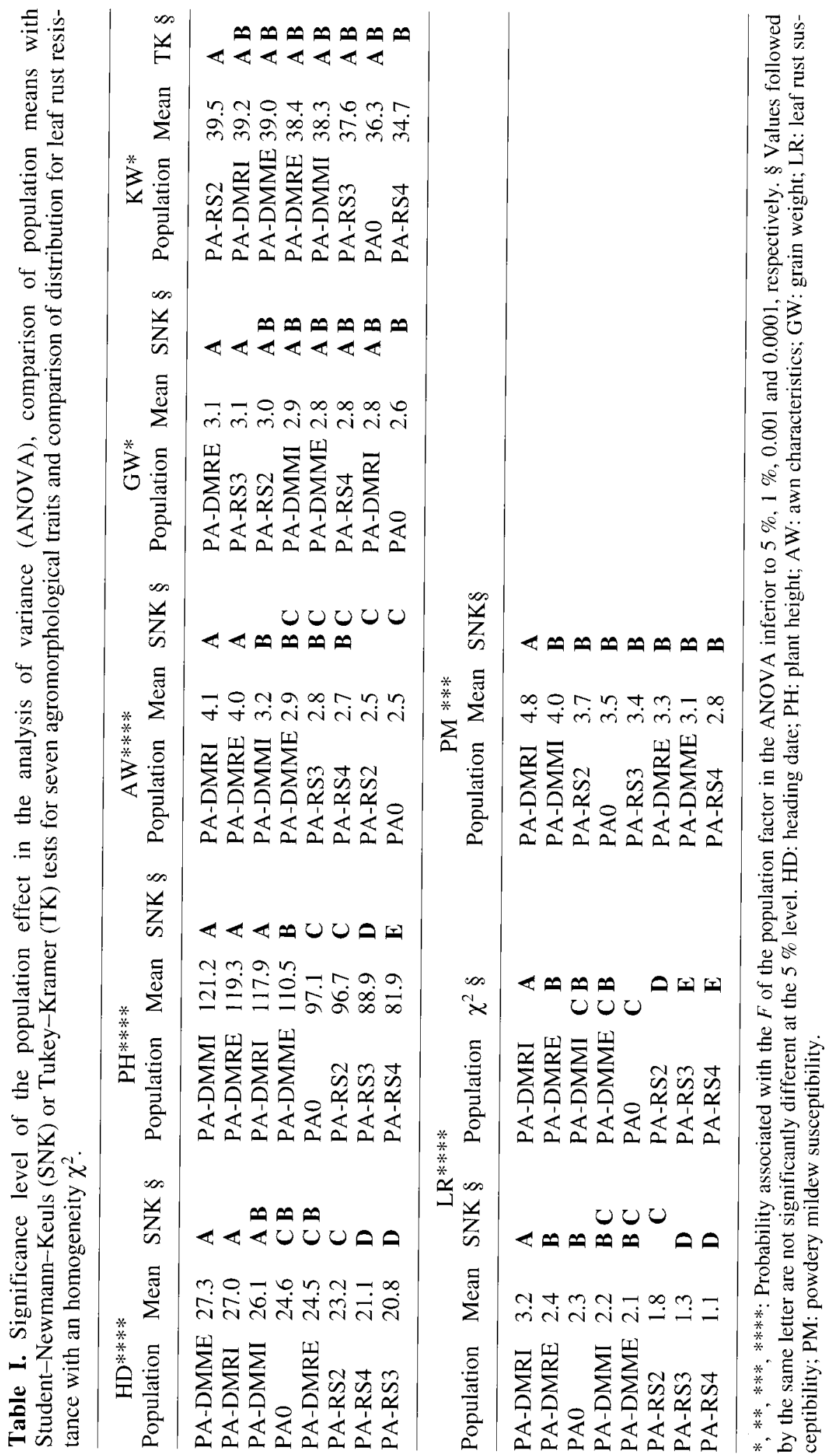


Within population genetic variance for Heading Date
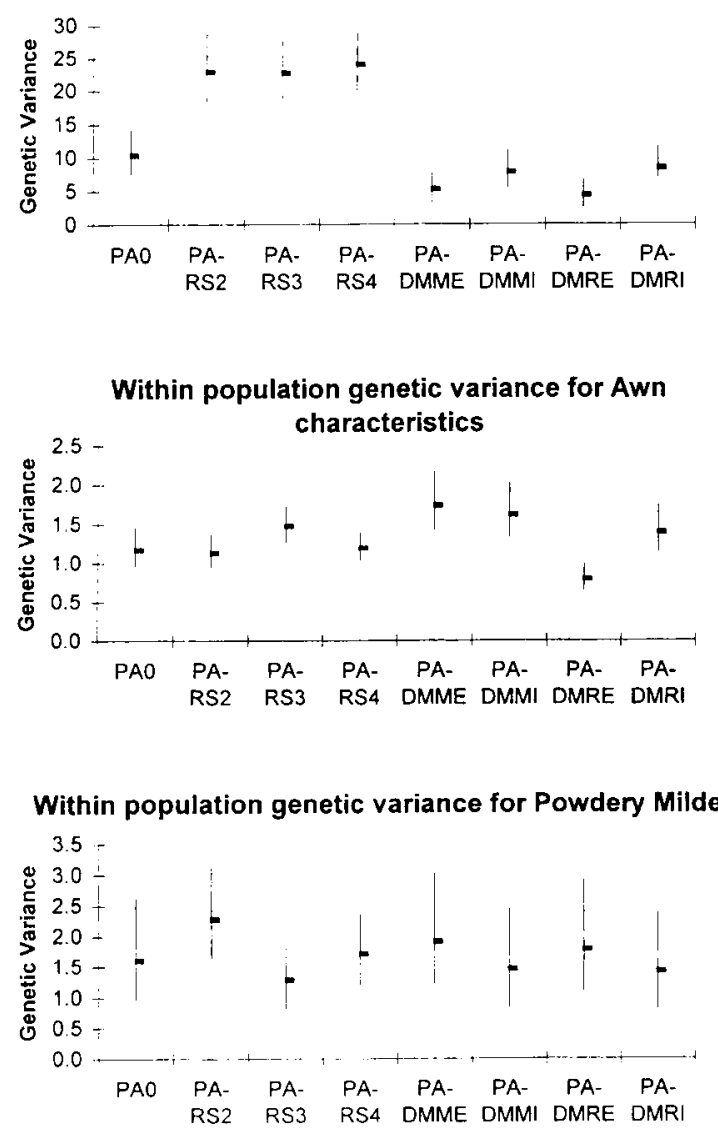

Within population genetic variance for Plant Height

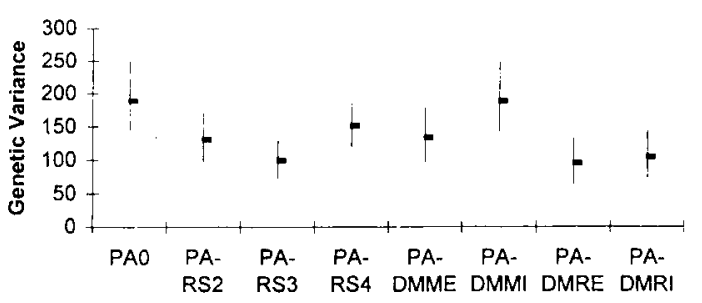

Within population total variance for Leaf Rust

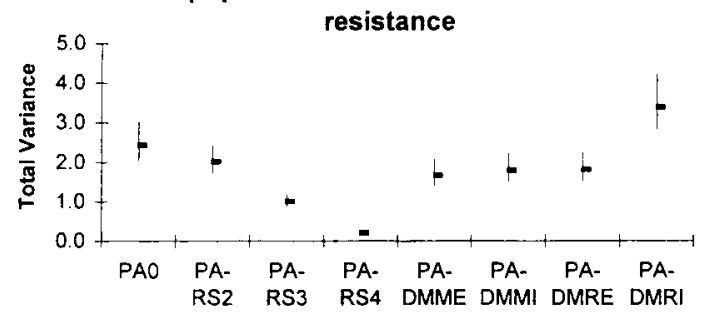

Within population genetic variance for Grain Weight

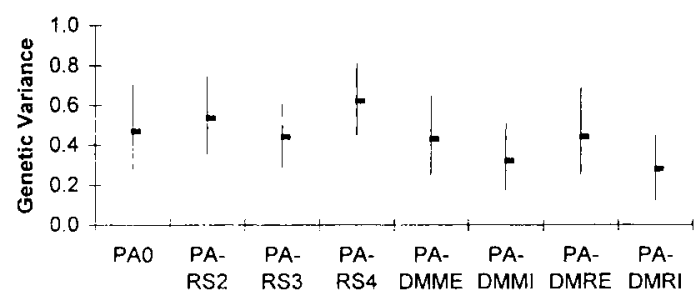

Figure 1. Genetic within-population variance for heading date, plant height, awn characteristics, powdery mildew susceptibility (resistance) and grain weight, and total within-population variance for leaf rust susceptibility (resistance), with their standard error, for eight PA populations (PA0, PA-RS2, PA-RS3, PA-RS4, PA-DMME, PA-DMMI, PA-DMRE and PA-DMRI).

The evolution of awn characteristics (AW) was somewhat surprising. This trait was supposed to be neutral with regard to selection in both the RS scheme and the DM programme. Though not all the differences were significant, the DM populations, and the RS populations to a lesser extent, all had more bearded plants than PA0 (table I). Three of the DM populations were significantly more bearded than PA0. A strong site effect could be found in the specific comparison of the four DM populations, the Rennes populations being more bearded (table II). The increase in the frequency of bearded plants was observed previously by David et al. [6] on the PA and PB (another genetic pool present in the DM network) populations. This was also found on the barley CCII composite by Allard [1]. Hence, the important evolution in DM could be explained either by the fact that this trait was involved by itself in the selective value of the plants or by the fact that the locus controlling the trait was linked to loci controlling other selected traits. It can be noted, however, that AW was not correlated with any other measured trait in the initial PA0 population (data not shown). 
Table II. Significance levels and means of site and farming condition effects in the analysis of variance (ANOVA) on the four dynamic conservation populations.

\begin{tabular}{ccccccc}
\hline Traits & $\begin{array}{c}\text { AW } \\
\text { population }\end{array}$ & Mean & $\begin{array}{c}\text { LR } \\
\text { population }\end{array}$ & Mean & $\begin{array}{c}\text { PM } \\
\text { population }\end{array}$ & Mean \\
\hline Site effect & *** & & & & $\mathrm{ns}$ \\
& PA-DMR & 4.0 & PA-DMR & 2.8 & & \\
Farming condition & PA-DMM & 3.0 & PA-DMM & 2.1 & & $* * *$ \\
effect & ns & & PA-DMI & 2.7 & PA-DMI & 4.4 \\
& & & PA-DME & 2.2 & PA-DME & 3.2 \\
\hline
\end{tabular}

Only traits with significant effect are presented. ns, *,**,***: Probability associated with the $F$ of each factor in the ANOVA, respectively, not significant, inferior to $5 \%, 1 \%$ and 0.001 . See table I for abbreviations.

\subsection{Evolution of the yield components}

Grain weight per spike (GW) and kernel weight (KW) were not much differentiated among populations (table I). For GW, all the populations showed a higher (but not always significantly higher) mean than PA0. This general increase of GW led to a high similarity of DM and RS populations. The mean of the four DM populations was significantly greater than the PA0 mean (2.9 versus 2.6) at a $1 \%$ level. The PA-RS3 (but not the PA-RS4) also had a significantly higher mean than PA0 (table I). For KW, results were still less clear. The specific comparison of the four DM populations against PA0 (38.7 versus 36.3) provided the only significant trend. However, it is important to note that only four measurements of $\mathrm{KW}$ were available for each population. These results for KW and GW are to be taken cautiously since the experimental conditions were far from the usual conditions used for yield evaluation: low density of plants, competition within heterogeneous populations and no fungicide treatment. Particularly, the shorter plants of the last cycles for RS populations might have been depressed by their neighbours. However, estimated in these conditions, we found a positive effect of natural selection on GW.

\subsection{Evolution of the disease susceptibility traits}

The comparison of population means for leaf rust susceptibility (LR) showed a strong differentiation between the DM and RS populations (table I). The average level of resistance of PA-DMRI significantly decreased with regard to the initial population. The three other DM populations could not be distinguished from PA0. On the contrary, the three RS populations showed a significantly higher level of resistance than PA0, PA-RS3 and PA-RS4, being even more resistant than PA-RS2. The homogeneity $\chi^{2}$ test on the distributions led to the detection of some additional differences. Both DM populations from Rennes proved to be different from PA0 and the three RS populations could be distinguished from all the DM populations (table I). The comparison of the sites and farming conditions either with the SNK test on the means or with a $\chi^{2}$ on the distributions showed a strong discrimination. The populations maintained under extensive farming conditions (without fungicides) remained more resistant than the other two (table II). The populations from Le Moulon were more resistant than those from Rennes and presented a distribution closer to that of the initial population PA0. The leaf rust selection pressure was usually not very strong in Rennes and Le Moulon. Actually, the DM populations main- 
tained in the sites of the South of France where leaf rust attacks are frequent might have evolved towards a higher resistance. Three DM populations showed a slight decrease of their within-population variance whereas PA-DMRI, which became less resistant than PA0, had a much larger variance. For the RS populations, the strong increase in the resistance level through the selection cycles gave evidence of the efficiency of selection for this trait in the RS scheme. It can be noted that this increase in the resistance level was associated with a drastic decrease in the within-population variance figure 1). In the fourth cycle, the variance was close to 0 . It is not surprising that variability is lost when the population tends to be completely resistant.

For the powdery mildew resistance (PM), only one population (PA-DMRI) could be separated from the others (table I). The means of the DM populations were distributed on both sides of the PA0 mean, and the means of the RS populations tended (but not in a significant way) to decrease through the selection cycles. The contrast between PA-RS4 and PA0 was found significant at the $10 \%$ level. Although there was no clear divergence between DM and RS populations for this trait, the contrast between the four DM populations and the three RS populations (3.8 versus 3.3) was found significant at the $5 \%$ level. In the specific comparison among the four DM populations, a strong farming condition effect was detected (table $I I$ ). The results already observed for LR were still enhanced for PM. The advantage of using extensive conditions in the multiplication of the DM populations had not, up to now, been demonstrated on the totality of the network sites. However, the clearly higher resistance level of the extensive populations based on the Rennes and Le Moulon sites demonstrated the benefit of the extensive condition and the effect of natural selection in such systems. On the other hand, the site effect was not significant for PM although the populations from Le Moulon were both more resistant than the corresponding Rennes populations. The higher resistance to both pathogens of the Le Moulon populations may be due to a better adaptation of these populations to the parasitic populations present at Le Moulon. This could be confirmed by repeating the same experi- ment at Rennes. The very different behaviour of the populations for the two diseases may be related to the differences in stability of the pathogens populations from one year to the other. The populations of leaf rust pathogens are quite stable over the years whereas the populations of PM seem to be more variable. Hence, response to selection on the midterm (about 10 years) is expected to be stronger for leaf rust than for PM.

\subsection{Multitrait level}

These results were illustrated by a canonical discriminant analysis (figure 2). The barycentres of the eight populations obtained from the multivariate analysis were plotted on the two planes defined, respectively, by the first and second canonical variables and by the first and third canonical variable. The RS and DM populations appeared clearly separated on the first canonical component, both groups being apart from the initial PA0 population. Projected on axis 1, the mean of the four DM populations was nearly as far from PA0 as PA-RS4. The opposition between RS and PA0 on the one hand, and DM, on the other hand, was mainly related to differences for PH, HD and LR. According to the second canonical variable, RS and DM populations have been evolving in the same way. The common evolutions were mostly due to increases in grain weight, percentage of bearded plants and leaf rust resistance. The first two axes showed that the RS populations were progressively moving away from PA0 through the cycles of selection. The third canonical component specifically contrasted the PA-DMRI population with the PA-DMME. This observation was strengthened (data not shown) if the analysis was restricted to the four DM populations. This separation was related to the higher susceptibility to both diseases of PA-DMRI and to its higher percentage of bearded plants.

\section{DISCUSSION}

Our results show that the populations derived from DM and those derived from RS can be sharply differentiated on the basis of a few agromorpholog- 

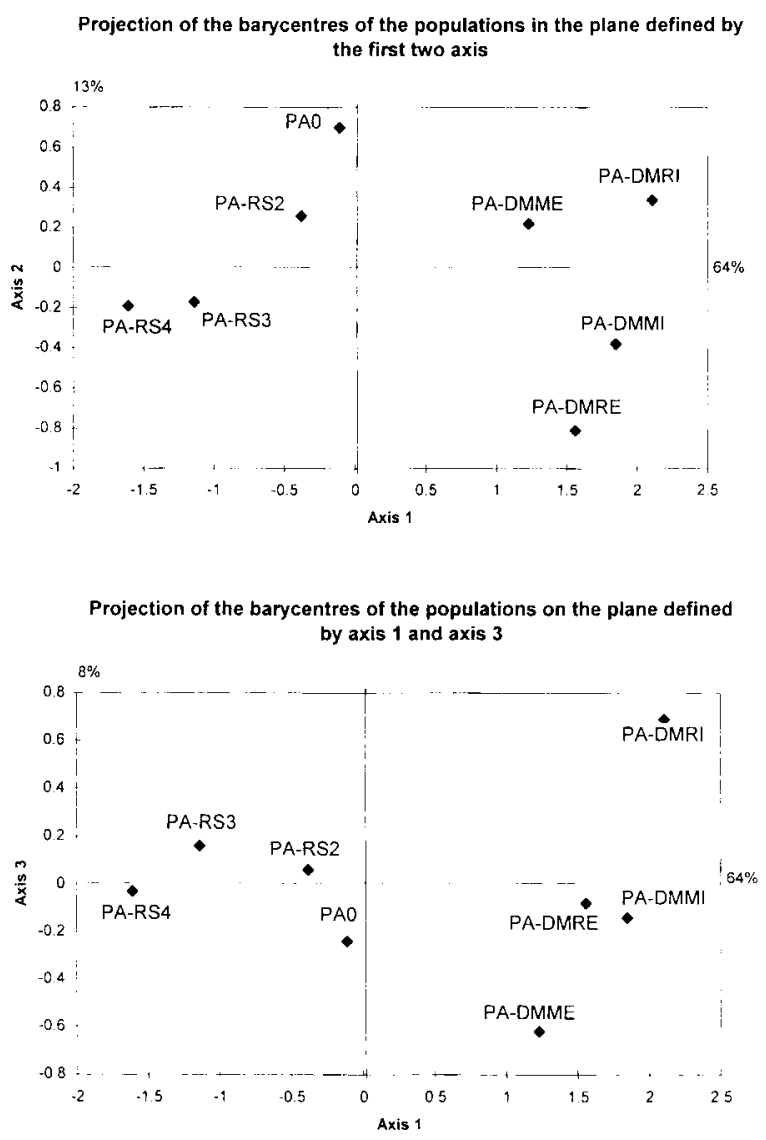

Canonical correlations of the variables with the three axis
\begin{tabular}{|c|ccc|}
\hline Variables & Axis 1 & Axis 2 & Axis 3 \\
\hline HD & 0.90 & 0.31 & -0.24 \\
PH & 0.99 & -0.11 & -0.03 \\
AW & 0.74 & -0.35 & 0.42 \\
GW & -0.31 & -0.38 & 0.20 \\
LR & 0.82 & 0.50 & 0.19 \\
PM & 0.65 & 0.32 & 0.62 \\
\hline
\end{tabular}

Figure 2. Projection of the barycentres of eight $P A$ populations (PA0, PA-RS2, PA-RS3, PA-RS4, PA-DMME, PA-DMRI, PA-DMMI and PA-DMRE) on the first two planes determined with a canonical discriminant analysis performed on six variables: heading date (HD), plant height (PH), awn characteristics (AW), grain weight (GW), leaf rust susceptibility (LR) and powdery mildew susceptibility (PM).

ical traits. For three traits (HD, PH and LR), natural selection and artificial selection led to opposite evolutions, even though for HD and LR most of the DM populations were rather close to the initial population PA0. For AW and GW, populations have evolved in the same direction but for AW, change was faster in DM than RS, so populations of DM appeared somewhat different. Such high differentiation did not completely support the use of the DM populations as a source of variability for RS since some evolution in the DM system was rather negative.

In particular, the case of $\mathrm{PH}$ is quite worrying. Whereas $\mathrm{PH}$ in RS populations greatly decreased due to the breeding effort, a considerable increase in height was noted in all the DM populations as a consequence of interplant competition. PH has long been associated with intergenotypic competition ability in cereal $[16,19]$. Yet, the increase in height was greater and more rapid in our populations than in the barley composite cross populations cultivated under comparable growing conditions $[1,29]$. This was mainly due to the elimination of the dwarfing genes as demonstrated by Pontis [27]. The undesirable evolution of height makes the agronomic evaluation of DM genotypes difficult (because of lodging) and limits its possible use in the breeding of elite lines. As emphasized by Chapman [4] after Donald and Hamblin [7], plant breeding success in recent years depended on features that diminish intergenotypic competitive ability, such as dwarf stature or reduced tillering. Hence, alleles conferring these characteristics are strongly counterselected in heterogeneous populations and need constant human intervention to be preserved. Moreover, we can presume that the genes selected in a tall plant context may not be expressed in the same way in the genetic background of improved short lines because dwarfing genes display pleiotropic effects over other traits $[10,26]$. This led us to consider it essential to create, within a dynamic management programme, a compartment where constant artificial selection would be applied to preserve the cultivated pattern of the populations. Such a compartment would constitute the only reservoir for some genes of agronomic interest, otherwise eliminated by natural selection.

The divergent evolution of HD in the populations under natural and artificial selection should be more precisely studied. The trend towards earliness of the RS populations can hardly be explained by the evaluation and selection in the Clermont-Ferrand location (1 year per cycle of trilocal evaluation). This result may possibly show deeper differences in the 
mechanisms of the two kinds of selection. Frequent recombinations in the recurrent selection cycle lead to the breaking of the gene associations and to a more efficient selection on additivity than on additive by additive epistasis [14]. The low level of recombination in DM would be more efficient for selection on epistatic effects. This might have led to the selection of very different genotypes in both systems. In the specific case of HD, if it proves to be advisable, it seems easy to control the evolution of earliness in the DM populations. The plots just need to be harvested a little earlier than they have been up to now, at the end of the harvest time.

Genetic variability was maintained within the DM populations for AW, PM and LR. A slight decrease of variance could be detected for $\mathrm{PH}$ and GW and a very drastic loss was found for HD. The initial genetic variance was theoretically expected to decrease in each population due to genetic drift and selection. However, if the local selection pressures were different from one site to another, diversity was expected to be maintained at the level of the whole populations of the network. For example, after only 6 years of multiplication, David [5] found that $15 \%$ of the total genetic variance for HD was between populations (data for populations from seven multiplication sites). Although here we studied only four DM populations originating from two sites at the same latitude, the variation between populations constituted $17 \%$ of the total genetic variance (after 8 years of multiplication). Hence, the total genetic variance for these four DM populations was 7.8 compared with the initial genetic variance of PA0 of 10.4 (cf. figure 1). It seems that during the 2 additional years of multiplication, differentiation between populations had been going on. Hence, these results, though concerning only four populations, confirm the efficiency of the DM network to preserve the genetic variability, except for traits such as $\mathrm{PH}$ which are highly involved in competition between plants.

Apart from LR and, to a lesser extent, $\mathrm{PH}$, the RS programme was successful in maintaining genetic variability. This can be explained by the multisite and multitrait selection combined with the frequent intercrossing of the numerous families (about 80) selected at each cycle. Moreover, such frequent recombinations are likely to lead to the redistribution of the epistatic variance. Hence, as epistasis was found to be important for many traits in wheat and particularly for HD [13], the increased genetic variance for this trait could be related to such a phenomenon. We also considered the possibility of a positive effect of the introduction of exogenous lines in the third cycle on the maintenance of the variance, but this was ruled out since no increase in variance could be observed in PA-RS3 for any trait except perhaps for AW.

In the case of quantitative traits, a slow decrease of the genetic variance was expected to be associated with the response to selection. The rapid increase for resistance to leaf rust observed in RS, combined with considerable loss of variability, suggests that resistance might have been realized through the fixation of one or few major genes. On the other hand, the resistance of the DM populations was maintained at a quite good level with a selection pressure lower than the one applied in the RS scheme, suggesting that the mechanisms involved in the DM system could be more multigenic. It is therefore important to characterize the genes that control the resistance developed in the RS populations as well as those involved in the resistance of the DM populations. The diversity of resistance genes is expected to be maintained in the DM system thanks to the distinct pathogenic selective pressures present in the different sites of the network. Such evolution has been observed by Le Boulc'h et al. [22] in the case of PM. If the characterization of genes confirms our hypothesis, the DM populations (especially those cultivated under extensive farming conditions, i.e. no fungicides) could constitute a valuable genetic resource for recurrent selection.

For such utilization of a DM system as well as for an efficient maintenance of genetic diversity, it is essential to choose sites with contrasted characteristics (farming and agroclimatic conditions, selective pathogenic pressures) in order to compensate for the local loss of variability through intersite differentiation. The use of the DM populations as genetic resources will also require the best possible characterization of the local conditions and the quantitative and qualitative nature of the pathogen pressures. Then, according to the needs of the RS 
scheme, the screening of a sample of plants from the appropriate DM population, known to be particularly resistant for one or various pathogens, could provide the progenitors to introduce them in the RS programme. The proportion of DM parents to introduce should be limited but has to be precisely determined. The effective integration of some parts of these extraneous genomes could be controlled by the characterization of the subsequent generations with molecular markers or with resistance genes themselves.

Even though our study of RS and DM systems revealed significant evolution at the phenotypic level, the investigation of the genotypic level is needed in order to reach a better understanding of the causes of the organization and evolution of genetic variability. We are now considering the evolution of the frequencies of resistance genes in the populations, while the evaluation of neutral diversity using molecular markers is in progress. This will make it possible to estimate the effects of selective pressures over the network and over the wheat genome. These approaches aim at rationalizing the dynamic management of variability by adjusting DM population sizes and controlling gene flow between DM populations and from DM to RS programmes.

Acknowledgements: The authors thank N. Galic and M.-T. Marcombe for technical help in the agronomic experiment.

\section{REFERENCES}

[1] Allard R.W., Genetic changes associated with the evolution of adaptedness in cultivated plants and their wild progenitors, J. Hered. 79 (1988) 235-238.

[2] Brabant P., Kervella J., Doussinault G., Picard E., Rousset M., Influence du premier cycle de sélection récurrente appliqué à une population de blé tendre d'hiver, Agronomie 11 (1991) 473-482.

[3] Burton J.W., Koinange E.M.K., Brim C.A., Recurrent selfed progeny selection for yield in soybean using genetic male sterility, Crop Sci. 30 (1990) 12221226 .

[4] Chapman C.G.D., Collection strategies for the wild relatives of field crops, in: Brown A.H.D., Frankel
O.H., Marshall D.R., Williams J.T. (Eds.), The Use of Plant Genetic Resources, Cambridge University Press, 1989, pp. 263-279.

[5] David J.L., Approche méthodologique d'une gestion dynamique des ressources génétiques chez le blé tendre (Triticum aestivam L.), thèse, Institut national agronomique Paris Grignon, 1992.

[6] David J.L., Savy Y., Trottet M., Pichon M., Méthode de gestion dynamique de la variabilité génétique. Exemple d'un réseau expérimental de populations composites de blé tendre, in : BRG, Complexes d'espèces, flux de gènes et ressources génétique, Paris, 1992, pp. 337-350.

[7] Donald C.M., Hamblin J,, The convergent evolution of annual seed crops in agriculture, Adv. Agron. 36 (1983) 97-143.

[8] Dosba F., Doussinault G., Les lignées d'addition Blé-Aegilops ventricosa. I. Etude du comportement visà-vis du piétin-verse des différentes lignées obtenues, Agronomie 1 (1981) 503-511.

[9] Enjalbert J., Goldringer I., David J.L., Brabant P., The relevance of outcrossing for the dynamic management of genetic resources in predominantly selfing Triticum aestivum (bread wheat), Genet. Sel. Evol. (in press).

[10] Gale M.D., Youssefian S., Dwarfing genes in wheat, in: Russel G.E. (Ed.), Progress in Plant Breeding, Butterworths, London, 1985, pp. 1-34.

[11] Gallais A., Amélioration des populations, méthodes de sélection et création de variétés. I. Synthèse sur les problèmes généraux et sur les bases théoriques pour la sélection récurrente intra-population, Ann. Amelior. Plantes 27 (3) (1977) 281-329.

[12] Goldringer I., Brabant P., Sélection récurrente chez les autogames pour l'amélioration des variétés lignées pures : une revue bibliographique II, Agronomie 13 (1993) 561-577.

[13] Goldringer I., Brabant P., Gallais A., Estimation of additive and epistatic genetic parameters in a population of doubled-haploid lines of wheat (Triticum aestiv'um L.), Heredity 79 (1997) 60-71.

[14] Goldringer I., Brabant P., Gallais A., Theoretical study of the relative efficiency of recurrent selection methods applied to self-pollinated species when epistasis is considered, in: Proceedings of the 10th EUCARPIA Meeting, Section Biometrics in Plant Breeding, Poznan, Poland, 1997.

[15] Hallauer A.R., Miranda J.B., Quantitative Genetics in Maize Breeding, Iowa State University Press, Ames, IA, 1981. 
[16] Hamblin J., Donald C.M., The relationship between plant form, competitive ability and grain yield in a barley cross, Euphytica 23 (1974) 535-542.

[17] Henry J.P., Pontis C., David J.L., Gouyon P.H., An experiment on dynamic conservation of genetic resources with metapopulations, in: Seitz A., Loeschcke V. (Eds.), Species Conservation: A Population Biological Approach, Birkhaüser Verlag, Basel, 1991, pp. 185-198.

[18] Hospital F., Charcosset A., Marker-assisted introgression of quantitative trait loci, Genetics 147 (1997) 1469-1485.

[19] Jensen N.F., Federer W.T., Adjacent row competition in wheat, Crop Sci. 459 (1964) 641-645.

[20] Kervella J., Goldringer I., Brabant P., Sélection récurrente chez les autogames pour l'amélioration des variétés lignées pures : une revue bibliographique, Agronomie 11 (1991) 335-352.

[21] Kramer C.J., Extension of multiple range tests to group means with unequal numbers of replications, Biometrics 12 (1956) 307-310.

[22] Le Boulc'h V., David J.L., Brabant P., De Vallavieille-Pope C., Dynamic conservation of variability: responses of wheat populations to different selective forces including powdery mildew, Genet. Sel. Evol. 26 (Suppl. 1) (1994) 221-240.

[23] Lefebvre V., Palloix A., Both epistatic and additive effects of QTLs are involved in polygenic induced resistance to disease: a case study, the interaction pepper - Phytophthora capsici leonian, Theor. Appl. Genet. 93 (1996) 503-511.

[24] Marocco A., Cattivelli L., Delogu G., Lorenzoni C., Stanca A.M., Performance of S2 winter barley progenies from original and improved populations developped via recurrent selection, Plant Breeding 108 (1992) 250-255.
[25] Pham J.L., Brabant P., David J.L., Henry J.P., Le Boulc'h V., Gallais A., Gouyon P.H., Pontis C., Some lessons drawn from twelve years of dynamic management of winter wheat populations (Triticum aestivum L.) in France, Bocconea 7 (1997) 219-226.

[26] Pinthus M.J., Gale M.D., The effects of gibberellin-insensitive dwarfing alleles in wheat on grain weight and protein content, Theor. Appl. Genet. 79 (1990) 108-112.

[27] Pontis C., Utilisation de marqueurs génétiques pour le suivi de la variabilité de 3 composites de Blé tendre d'hiver (Triticum aestivum L.) menés en gestion dynamique, thèse, Institut national agronomique Paris Grignon, 1992.

[28] Rose J.L., Butler D.G., Ryley M.H., Yield improvement in soybeans using recurrent selection, Aust. J. Agric. Res. 43 (1992) 135-144.

[29] Suneson J., Registration of barley composite crosses, Crop Sci. 9 (1969) 395-396.

[30] Tanksley S.D., Nelson J.C., Advanced backeross QTL analysis: a method for the simultaneous discovery and transfer of valuable QTLs from unadapted germplasm into elite breeding lines, Theor. Appl. Genet. 92 (1996) 191-203.

[31] Thomas G., Rousset M., Pichon M., Trottet M., Doussinault G., Picard E., Méthodologie de l'amélioration de blé tendre (Triticum aestivum L.). I. Création par croisements et analyse d'une population artificielle a 16 parents, base de cette étude méthodologique, Agronomie 11 (1991) 359-368.

[32] Thomas G., Doussinault G., Trottet M., Méthodologie de l'amélioration du blé tendre (Triticum aestivum L.). II. Etude et analyse de deux premiers cycles de sélection récurrente, Agronomie 11 (1991) 457-472. 